\title{
EDITORIAL NOTE \\ The effect of stress on sleep quality in teenagers, the analysis of metal contamination due to heaps of steel-slag accumulation in southern Madrid (Spain), and a review of the mechanisms of glutamine action during severe illnesses
}

\author{
ALEXANDER W. A. KELLNER \\ Editor-in-chief
}

Researchers worldwide have pointed out the effects that stress produces upon the society. However, there are particular stress situations that affect the growing up of an individual. As pointed out several times in the literature, human development itself can be regarded as a source of stress, starting with the child's learning process followed by the physical and cognitive changes during the adolescence (e.g., Pereira and Tricoli 2003). But how does stress affect teenagers? More specifically, can any relation be established between stress, sleep quality and school performance?

Although this subject has been addressed by researchers in some countries, not much has been done in Brazil so far. In the present issue of the Anais da Academia Brasileira de Ciências (AABC), Gema Mesquita and Rubens Reimão, both from the Departamento da Saúde da Criança e do Adolescente of the Universidade de Campinas (UNICAMP) of Campinas (São Paulo), have shed some light on this problem by trying to understand the effect of stress on the sleep quality of teenagers in Brazil (Mesquita and Reimão 2010). The authors have based their research on 160 students between 15 and 18 years and applied the Pittsburgh Sleep Quality Index (PSQI) in order to recover information about sleep quality. They further used the Lipp Inventory of Stress Symptoms in order to establish stress symptoms in the participants. Their results contribute to the goal to understand child and adolescent sleep disorders and might help authorities in mitigate negative effects.

Another problem that affects modern life is environmental pollution. One source that is not adequately understood is the pollution caused by iron and steel production due to the significant steel slag accumulation achieved along the years. In the past, the society was not fully aware on how such industrial activities could negatively affect the environment and there was a general lack of pollution control. But presently authorities are getting more concerned since soil pollution might affect farmlands and their production.

Javier Garcia-Guinea from Museo Nacional de Ciencias Naturales of Madrid and colleagues have studied the soil contamination with heavy metals due to heaps of steel-slag accumulation resulted in over 40 years of iron and steal production in the region of Getafe, southern part of Madrid (Garcia-Guinea et al. 2010). They have collected several soil samples from different points of the area that were analyzed by conventional mineralogical and geochemical methods with the purpose to establish the degree of contamination (Gunst et al. 2000). The results of this kind of research can help local authorities in establishing plans for remediation in order to avoid risk to human health.

Another important contribution published in the present issue of the AABC is the research on the effects of amino acid glutamine (Gln) during critical illnesses. Gisele Oliveira of the Instituto de Biofisica Carlos Chagas Filho of the Universidade Federal do Rio de Janeiro (UFRJ) and colleagues have critically reviewed the main studies done in the last 10 years regarding the benefits provided by glutamine in patients (Oliveira et al. 2010). As pointed out in 
the literature, patients can experience low mucosal glutamine concentration (among others) during severe illnesses (Oudemans-van Straaten et al. 2001). In those cases, application of glutamine has improved the patient's condition, but as the present study shows, the results vary depending on the dose and route of glutamine administration. Oliveira et al. (2010) point out that more research is needed to fully understand the causes of the benefits in order to improve this therapy.

\section{REFERENCES}

Garcia-Guinea J, Correcher V, Recio-Vazquez L, Crespo-Feo E, Gonzalez-Martin R and Tormo L. 2010. Influence of accumulation of heaps of steel slag on the environment: determination of heavy metals content in the soils. An Acad Bras Cienc 82: 267-277.

Gunst S, Wenbruch S, Wentzel M, Ortner HM, Skogstad A, Hetland S and Thomassen Y. 2000. Chemical composition of individual aerosol particles in workplace air during production of manganese alloys. J Environ Monitor 2: $65-71$.

Mesquita G And Reimão R. 2010. Stress and sleep quality in high school Brazilian adolescents. An Acad Bras Cienc 82: $545-551$.

Oliveira GP, Dias CM, Pelosi P AND Rocco PRM. 2010. Understanding the mechanisms of glutamine action in critically ill patients. An Acad Bras Cienc 82: 417-430.

Oudemans-van Straaten HM, Bosman RJ, Treskes M, Van Der Spoel HJ and Zandstra DF. 2001. Plasma depletion and patient outcome in acute ICU admissions. Intensive Care Med 27: 84-90.

Pereira MMB And Tricoli VAC. 2003. A influência do meio ambiente e de práticas parenterais na vulnerabilidade ao stress. In: LiPP MN. Mecanismos Neuropsicológicos do stress: Teoria e aplicações clínicas. São Paulo, Casa do Psicólogo, p. $68-70$. 